\title{
Alterações fisiológicas, qualitativas e microbiológicas durante o armazenamento de abóbora minimamente processada em diferentes tipos de corte ${ }^{1}$
}

\author{
Fabiana F Sasaki²; Juan S del Aguila; Cláudio Rosa Gallo; Edwin Moisés Marcos Ortega; Angelo Pedro \\ Jacomino; Ricardo Alfredo Kluge ${ }^{3}$ \\ USP-ESALQ, C. Postal 9, 13418-900 Piracicaba-SP; E-mail: fsasaki@ esalq.usp.br; ${ }^{2}$ Bolsista Fapesp; ${ }^{3}$ Bolsista CNPq
}

\section{RESUMO}

O presente estudo teve como objetivo verificar as alterações fisiológicas, qualitativas e microbiológicas de abóbora (Cucurbita moschata) cv. Canhão minimamente processada submetida aos cortes em meia-rodela, cubos e retalhos, e armazenadas a $5^{\circ} \mathrm{C}$ e $85-90 \%$ de UR durante 12 dias. O delineamento experimental foi inteiramente casualizado, com quatro repetições (uma bandeja por tratamento). A taxa respiratória dos três tipos de corte apresentaram valores entre 3,2 e 7,5 mL CO $\mathrm{kg}^{-1} \mathrm{~h}^{-1}$. Os cortes em cubo e retalho apresentaram maiores taxas de produção de etileno, atingindo valores de $4,05 \mu \mathrm{L} \mathrm{C}_{2} \mathrm{H}_{4} \mathrm{~kg}^{-1} \mathrm{~h}^{-1} \mathrm{e} 3,82 \mu \mathrm{L} \mathrm{C}_{2} \mathrm{H}_{4} \mathrm{~kg}^{-1} \mathrm{~h}^{-1}$, respectivamente. Os cortes em retalho apresentou alterações qualitativas indesejáveis, como maior perda de massa $(2,66 \%)$, maiores reduções nos teores de sólidos solúveis, de ácido ascórbico e de carotenóides, além de propiciar maior crescimento de bactérias psicrotróficas. Os cortes em cubo e meia-rodela apresentaram melhores resultados em relação aos cortes em retalho para a maioria das variáveis físicas, químicas e físico-químicas analisadas e para contagens de bactérias psicrotróficas. Não foram observados coliformes e Salmonella nos três tipos de corte durante o armazenamento.

Palavras-chave: Cucurbita moschata, carotenóides, respiração, etileno, microbiologia.

\begin{abstract}
Physiological, qualitative and microbiological changes in minimally processed squash submitted to different cut types

The present work was carried out to check the physiological, qualitative and microbiological alterations of minimally processed squash (Cucurbita moschata) cv. Canhão submitted to different cut types (middle-circle, cube and shred). Minimally processed squash was stored at $5^{\circ} \mathrm{C}$ and $85-90 \%$ relative humidity during 12 days. A completely randomized experimental design with four replicates of one package was used. Respiratory rate of the three cuts ranged from 3.2 to $7.5 \mathrm{~mL} \mathrm{CO}_{2} \mathrm{~kg}^{-1} \mathrm{~h}^{-1}$. The cut in cube and shred showed higher ethylene production (4.05 and $3.82 \mu \mathrm{L} \mathrm{C}_{2} \mathrm{H}_{4} \mathrm{~kg}^{-1} \mathrm{~h}^{-1}$, respectively). The shredded squash showed undesired qualitative alterations, as higher weight loss $(2.66 \%)$, decrease in soluble solids amount, acid ascorbic and carotenoids. Besides, this cut increased growth of psychotropic bacteria. The cube and middle-circle cuts showed best results in relation to the physical, chemical and physicochemical analysis and psychotropic bacteria amount, when compared to the shred cut. No coliforms or Salmonella growth was observed during storage of the cut types.
\end{abstract}

Keywords: Cucurbita moschata Duch., ascorbic acid, carotenoids, respiration, ethylene, microbiology.

(Recebido para publicação em 24 de abril de 2005; aceito em 3 de maio de 2006)

\begin{abstract}
$\mathrm{A}^{\mathrm{s}}$ s frutas e hortaliças frescas minimamente processadas são produtos in natura que se tornam prontos para o consumo ou uso no preparo de outros pratos. Elas são, geralmente, descascadas ou cortadas, se necessário, lavadas e submetidas a processos de sanitização (Nguyen \& Carlin, 1994). O processamento pode incluir ainda o controle de $\mathrm{pH}$, a adição de antioxidantes, a imersão em água clorada, ou a combinação destes ou outros tratamentos com outros métodos de conservação (Wiley, 1997). O propósito dos alimentos minimamente processados é proporcionar ao consumidor produtos frutícolas e hortícolas convenientes, parecidos com os frescos e com vida útil prolongada.
\end{abstract}

Simultaneamente, esses produtos devem ser seguros do ponto de vista sanitário e manter sólida qualidade nutritiva e sensorial (Wiley, 1997). Os produtos minimamente processados são o segmento que mais cresce dentro do mercado varejista de alimentos. No entanto, o processamento mínimo ainda necessita de muitos estudos devido às dificuldades de manter uma boa qualidade durante períodos prolongados (SolivaFortuny \& Martin-Belloso, 2003).

Pertencente à família Cucurbitaceae e ao gênero Cucurbita, a abóbora (Cucurbita moschata Duch.) tem como centro de origem a região central do México estendendo-se até a Colômbia e a Venezuela. A abóbora tornou-se cos- mopolita, sendo a espécie mais importante na América tropical, pela área em que se expandiu e pela variabilidade (Casali et al., 1982; Filgueira, 2000). A abóbora contém (em $1 \mathrm{~kg}$ ) 1,3\% de fibras e $96 \%$ de água, com a seguinte composição: 40 calorias, $280 \mathrm{mg}$ de vitamina A, 700mg de vitamina B5, 100mg de vitamina $\mathrm{B} 2,55 \mathrm{mg}$ de vitamina $\mathrm{B}$, além de sais como cálcio, fósforo, potássio, sódio, ferro e enxofre (Luengo et al., 2000). As abóboras podem ser consumidas verdes ou maduras: as verdes são preparadas em pratos salgados e as maduras são utilizadas, geralmente, na elaboração de doces caseiros ou industrializados e também em diversos pratos salgados (Camargo Filho \&

${ }^{1}$ Parte da dissertação de mestrado do primeiro autor, apresentada à USP-ESALQ. 
Mazzei, 2003). De alto valor nutritivo, o consumo de abóbora não é maior devido ao grande tamanho dos frutos e a dificuldade no descascamento, tornando seu preparo muito trabalhoso. Por isso a oferta deste produto na forma minimamente processada é uma alternativa interessante para o mercado.

$\mathrm{O}$ efeito dos cortes ou injúrias provoca o rompimento de organelas, modifica a permeabilidade de célula, provoca desorganização celular, ativando a síntese de etileno e aumentando a respiração (Durigan \& Cassaro, 2000). O etileno proveniente do corte ("etileno de ferida") contribui para a biossíntese de enzimas envolvidas em alterações fisiológicas e bioquímicas associadas à senescência (Brecht, 1995).

Os tecidos fatiados, cuja superfície de exposição é maior, apresentam maiores taxas de respiração e, consequentemente, maiores alterações fisiológicas, bioquímicas e microbiológicas que o tecido inteiro (Porte \& Maia, 2001). Segundo Brecht (1995), quanto mais retalhada a alface, menor sua durabilidade. Entretanto, alface rasgada preserva-se melhor que a retalhada, pois exsuda menos seiva da célula. O mesmo autor afirma que tanto a intensidade dos cortes quanto a direção em que foram realizados interferiram na deterioração de pimentão verde minimamente processado, que foi mais lenta nos cortes transversais quando comparado aos longitudinais. Estes resultados parecem estar associados à maior solubilização da pectina na superfície das fatias longitudinais.

Com o objetivo de ampliar o conhecimento e atender as novas demandas do mercado por produtos minimamente processados, este trabalho se propôs a estudar as alterações decorrentes dos diferentes tipos de corte visando obter aquele que promova melhor manutenção da qualidade e maior tempo de conservação de abóbora minimamente processada.

\section{MATERIAL E MÉTODOS}

As abóboras maduras (Cucurbita moschata Duch.), cv. Canhão, foram adquiridas de produtor da região de Tupã-SP e trazidas ao Laboratório de
Pós-Colheita da USP-ESALQ. Antes de serem trazidas ao laboratório, as abóboras sofreram uma pré-seleção, sendo escolhidos os frutos sem injúrias e uniformes quanto ao tamanho, cor da casca e formato. Ao chegarem ao laboratório os frutos foram lavados com detergente e em água corrente, para retirada da sujeira grosseira. Em seguida, as abóboras sofreram uma desinfecção inicial com imersão em solução contendo 200 ppm de cloro ativo. Após a etapa de desinfecção, as abóboras foram colocadas em câmara fria a $10 \pm 1^{\circ} \mathrm{C}$ com $85-90 \%$ $\mathrm{UR}$, onde permaneceram por $16 \mathrm{~h}$.

$\mathrm{O}$ processamento foi realizado em câmara fria a $10 \pm 1^{\circ} \mathrm{C}$, utilizando-se roupas apropriadas (botas, avental, touca, máscara e luvas). A água de processamento foi destilada e refrigerada a $5^{\circ} \mathrm{C}$. A primeira etapa do processamento consistiu em corte em rodelas de 3,0 cm de espessura, utilizando-se faca de aço inoxidável afiada; remoção das sementes e parte esponjosa (com auxílio de colher). Em seguida, as abóboras foram cortadas em meia-rodela, cubo (arestas de $3 \times 3 \times 3 \mathrm{~cm}$ ) e retalhos ( $7 \mathrm{~mm}$ espessura), consistindo nos tratamentos. Os cortes em meia-rodela e cubos foram feitos com faca inoxidável afiada e o corte em retalho foi obtido com auxílio de uma processadora (Robout Coupe), com disco de corte na espessura de $7 \mathrm{~mm}$. Após os cortes, os pedaços foram lavados em água destilada (para retirada de excesso de suco celular), sanitizados com solução de cloro ativo a 200 ppm e enxaguados com água destilada contendo 3ppm de cloro ativo (para retirada do excesso de cloro). Em seguida, os pedaços foram deixados em escorredores domésticos para retirada do excesso de água, com exceção dos retalhos que foram centrifugados em centrífuga adaptada, durante $1 \mathrm{~min}$, com rotação média de $2000 \mathrm{rpm}$. Os pedaços foram pesados (300 g) e acondicionados em bandejas de poliestireno expandido e cobertos com PVC $(12 \mu \mathrm{m})$.

As embalagens foram armazenadas a $5 \pm 1^{\circ} \mathrm{C}$ e $85-90 \%$ UR. O período de armazenamento foi de 12 dias, sendo que as avaliações físico-químicas foram realizadas a cada três dias e as análises microbiológicas foram realizadas a cada seis dias. As variáveis analisadas foram: a) taxa respiratória: $150 \mathrm{~g}, 150 \mathrm{~g}$ e 300 $\mathrm{g}$ do produto (dependendo do tipo de corte) foram colocadas em frascos de vidro de capacidade de $600 \mathrm{~mL}, 600 \mathrm{~mL}$ e $1500 \mathrm{~mL}$, para os cortes em retalho, cubo e meia-rodela, respectivamente. Os frascos foram fechados hermeticamente $\left(1 \mathrm{~h}\right.$ a $\left.5^{\circ} \mathrm{C}\right)$, com tampas metálicas contendo um septo de silicone, por onde foram coletadas alíquotas de $1 \mathrm{~mL}$, com auxílio de seringa de vidro. As amostras coletadas foram injetadas em cromatógrafo a gás (Thermoquest GC Trace 2000) com detector de ionização de chama (FID), tendo nitrogênio como gás de arraste a um fluxo de $25 \mu \mathrm{L} / \mathrm{mi}^{-}$ nuto, as temperaturas foram $80^{\circ} \mathrm{C}$ na coluna, $100^{\circ} \mathrm{C}$ no injetor, $250^{\circ} \mathrm{C}$ no detector e $350^{\circ} \mathrm{C}$ na metanador, para medição de $\mathrm{CO}_{2}$. Os resultados foram expressos em mL $\mathrm{CO}_{2} \mathrm{~kg}^{-1} \mathrm{~h}^{-1}$; b) produção de etileno: foi utilizado o mesmo procedimento da análise da taxa respiratória, modificando-se temperatura do detector para $100^{\circ} \mathrm{C}$. Os frascos permaneceram fechados durante 2 horas. Os resultados foram expressos em $\mathrm{mL} \mathrm{C}_{2} \mathrm{H}_{4}$ $\mathrm{kg}^{-1} \mathrm{~h}^{-1}$; c) perda de massa: através de pesagem direta; d) teor de sólidos solúveis: por leitura direta em refratômetro digital (Atago), utilizando uma gota da abóbora centrifugada em centrífuga doméstica, sendo os resultados expressos em ${ }^{\circ}$ Brix; e) cor: determinada com colorímetro (Minolta), sendo as leituras realizadas em $\mathrm{L}, \mathrm{C}^{*}$ e $\mathrm{h}^{\mathrm{o}}$; f) acidez titulável, com os resultados expressos em \% de ácido málico (Carvalho et al., 1990); g) teor de ácido ascórbico, com os resultados expressos em mg $100 \mathrm{~g}^{-1}$ (Carvalho et al., 1990); h) teor de carotenóides totais, os resultados foram expressos em g/g (Rodriguez-Amaya \& Kimura, 2004); i) contagem de bactéria psicrotróficas: foi realizada através do método convencional com contagem em placa contendo meio PCA (Silva et al., 2001); contagem de coliformes totais e coliformes a $45^{\circ} \mathrm{C}$ : foi determinada pelo método do NMP, através da técnica de Tubos Múltiplos; k) detecção de Salmonella: foi realizada utilizando-se o Kit '1-2 Test', fabricado pela Biocontrol/USA, por tratar-se de um método oficial aprovado pela AOAC ("Association of Analytical Chemists International") para utilização em todo os tipos de alimentos. 


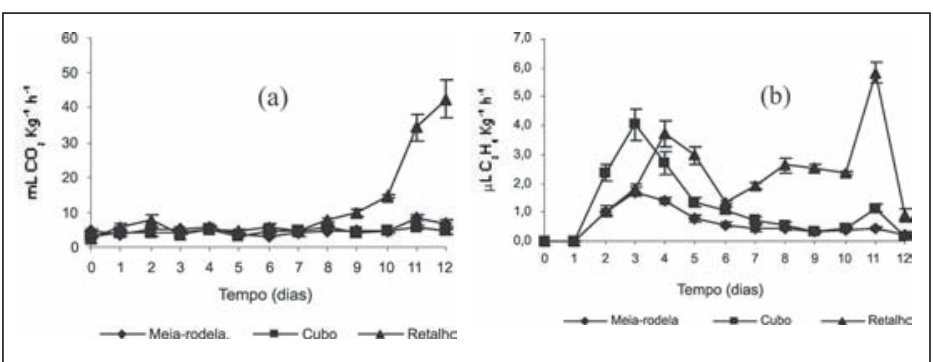

Figura 1. Taxa respiratória (a) e produção de etileno (b) em abóboras minimamente processadas, submetidas a diferentes tipos de corte e armazenadas a 5 ${ }^{*}$. Piracicaba, ESALQ, 2002. *Barras verticais representam o erro padrão da média. ESALQ, Piracicaba-SP.

Tabela 1. Contagem total de bactérias psicrotróficas em abóboras minimamente processadas em diferentes tipos de corte, armazenadas a $5^{\circ} \mathrm{C}$. Piracicaba, ESALQ, 2002.

\begin{tabular}{lccc}
\hline \multirow{2}{*}{ Tipos de corte } & \multicolumn{3}{c}{ Bactérias psicrotróficas (UFC/g) } \\
\cline { 2 - 4 } & $\mathbf{0}$ dias & $\mathbf{6}$ dias & $\mathbf{1 2}$ dias \\
\hline Retalhos & $5,0 \times 10$ & $4,2 \times 10^{5}$ & $2,2 \times 10^{7}$ \\
Cubos & $4,0 \times 10$ & $3,4 \times 10^{5}$ & $7,5 \times 10^{6}$ \\
Meia-rodela & $2,0 \times 10$ & $2,5 \times 10^{5}$ & $5,0 \times 10^{6}$ \\
\hline
\end{tabular}

O delineamento experimental utilizado foi inteiramente casualizado com esquema fatorial $3 \times 5$. Os fatores estudados foram tipos de corte (meia-rodela, cubos e retalhos) e tempo de armazenamento $(0 ; 3 ; 6 ; 9$ e 12 dias). Foram utilizadas quatro repetições por tratamento, sendo cada uma composta com bandejas com 300 g de abóbora minimamente processada. Para a caracterização do lote experimental (tempo zero), quatro amostras foram analisadas logo após o processamento mínimo do produto. Os resultados obtidos, das análises físicas, químicas e físico-químicas foram submetidos à análise do erro padrão. A diferença entre dois tratamentos maior que a soma dos dois erros padrões foi considerada significativa ( $\mathrm{P}<0,05)$ (Moretti et al., 2002). Para avaliação dos aspectos microbiológicos os resultados foram expressos em UFC/ $g$ de produto para bactérias psicrotróficas, $\mathrm{NMP} / \mathrm{g}$ para coliformes totais e presença ou ausência de Salmonella em $25 \mathrm{~g}$ de produto.

\section{RESULTADOS E DISCUSSÃO}

Até o $8^{\circ}$ dia de armazenamento, as taxas respiratórias se mantiveram constantes em todos os tratamentos, não havendo diferença entre os mesmos. A partir do $9^{\circ}$ dia somente o corte em retalhos apresentou uma elevação na taxa respiratória atingindo valores de 42,46 $\mathrm{mL} \mathrm{CO} \mathrm{kg}^{-1} \mathrm{~h}^{-1}$ (Figura 1a). Porte \& Maia (2001) afirmam que os tecidos fatiados, cuja superfície de exposição é maior, apresentam maiores taxas de respiração, porém isso não foi notado no presente trabalho. Talvez o fato das abóboras terem sido armazenadas sob refrigeração, na temperatura indicada como ideal por muitos autores, tenha diminuído os efeitos dos tipos de corte sobre taxa respiratória. Diversos autores afirmam que a temperatura exerce papel fundamental na respiração de vegetais, sendo que sua redução, também, reduz a taxa respiratória (Watada et al., 1990; Brecht, 1995; Porte \& Maia, 2001).

O tipo de corte teve influência sobre a produção de etileno em abóboras minimamente processadas, sendo que os corte em cubos e retalhos produziram maiores quantidades de etileno, chegando a picos de até $4,05 \mu \mathrm{L} \mathrm{C}_{2} \mathrm{H}_{4} \mathrm{~kg}^{-1} \mathrm{~h}^{-1}$, nos cubos, e $3,82 \mu \mathrm{L} \mathrm{C}_{2} \mathrm{H}_{4} \mathrm{~kg}^{-1} \mathrm{~h}^{-1}$ nos retalhos, no $3^{\circ}$ e $4^{\circ}$ dias, respectivamente. (Figura 1b). Durigan \& Cassaro (2000) afirmam que a desorganização celular provocada pelo corte ativa a produção de etileno aumentando a respiração. Nas abóboras minimamente processadas houve aumento da produção de etileno (Figura 1b), inclusive tendo relação com o tipo de corte, mas isto não refletiu em aumento da taxa respiratória, que só aumentou após 10 dias no corte em retalho (Figura 1a).

O corte em retalhos teve uma maior perda de massa, em relação aos cortes em meia-rodela e cubos (Figura 2a). Este processo ocorre durante todo período de armazenamento, sendo tanto maior quanto menor for o tamanho dos cortes (Izumi et al., 1996), devido a maior área de exposição dos cortes em tamanhos menores. Embora os valores tenham ficado aquém daqueles citados por Finger \& Vieira (1997) de 5 a $10 \%$ como críticos para as perdas de massa, as perdas foram de $0,87 \% ; 1,58 \%$ e $2,66 \%$ para os cortes em meia-rodela, cubo e retalho, respectivamente. Em melancia 'Crimson Sweet', não observou-se diferenças entre as melancias fatiadas em relação aos cubos a $3^{\circ} \mathrm{C}$ (Pinto, 2002). Porém em melões do tipo Orange Fresh as fatias perderam mais massa que os cubos quando armazenados a $3^{\circ} \mathrm{C}$ (Pinto, 2002).

$\mathrm{O}$ corte em retalho apresentou maior redução nos teores de sólidos solúveis, durante todo o período de armazenamento, mostrando reduções de até $2,45^{\circ}$ Brix entre o primeiro e o último dia. Isto ocorreu devido à maior intensidade de ferimentos provocados nesse tipo de corte tendo como consequiência maior descompartimentação celular e maior extravasamento do suco celular. O corte em cubos não apresentou variações nos teores de sólidos solúveis, ficando em torno de $5,33^{\circ}$ Brix. Já o corte em meiarodela apresentou um leve acréscimo nos teores de sólidos solúveis (Figura 2b). Ao contrário do ocorrido nas abóboras minimamente processadas, em melão minimamente processado, observou-se um aumento nos teores de sólidos solúveis de 0,68 e $0,16^{\circ}$ Brix, respectivamente para fatias e cubos, (Arruda et al., 2003).

O teor de acidez titulável apresentou-se baixo e com variações pouco expressivas ao longo do período de armazenamento, exceto no corte em retalho que apresentou um aumento nos valores de acidez total a partir do $6^{\circ}$ dia de armazenamento (Figura 2c).

Os ácidos orgânicos podem ser encontrados em frutas e hortaliças de for- 
ma natural ou acumulados, em conseqüência do processo de fermentação ou por adição dos mesmos durante processamento (Wiley, 1997). O aumento da acidez, observado no presente trabalho, pode estar associado ao processo fermentativo conforme citado por Wiley (1997). O corte em retalhos teve uma maior perda nos teores de ácido ascórbico durante o período de armazenamento, sendo seguido do corte em cubos, porque o primeiro aumenta a área de contato da abóbora com fatores do ambiente (calor, luz e oxigênio), além de ocasionar maior descompartimentação celular. Por possuir uma menor área de exposição ao ambiente, o corte em meia-rodela foi o que apresentou menores perdas de vitamina C (Figura 2d). Segundo Lee \& Kader (2000), a retenção de vitamina C é afetada pelo tipo de corte utilizado no produto. Os autores verificaram que a retenção de vitamina $\mathrm{C}$ em alfaces cortadas em pequenos pedaços por máquinas foram 25-63\% mais baixos do que as cortadas com as mãos.

As abóboras cortadas em retalhos tiveram uma redução drástica nos teores de carotenóides totais do dia do processamento (dia 0 ) para o $3^{\circ}$ dia de armazenamento. Após esse período, os valores tenderam a ficar estáveis até o final do período de armazenamento (Figura 2e). Isso pode ter ocorrido devido a maior intensidade de injúria causada por teste tipo de corte que provocou maior exposição dos tecidos à luz e ao oxigênio, que são fatores que degradam os carotenóides (Klein et al., 1985). Além disso, esse tipo de corte provocou maior extravazamento do suco celular e, provavelmente uma maior perda dos carotenóides que ficam estocados nos cromoplastos.

A luminosidade (L) das abóboras minimamente processadas com corte em meia-rodela e cubos permaneceu inalterada durante os 12 dias de armazenamento, enquanto que o corte em retalhos apresentou redução nos valores após 3 dias de armazenamento, porém, após este dia, os valores se mantiveram constantes (Figura 2f). Arruda et al. (2003) também não encontraram influência do tipo de corte nos valores de luminosidade de melões minimamen-

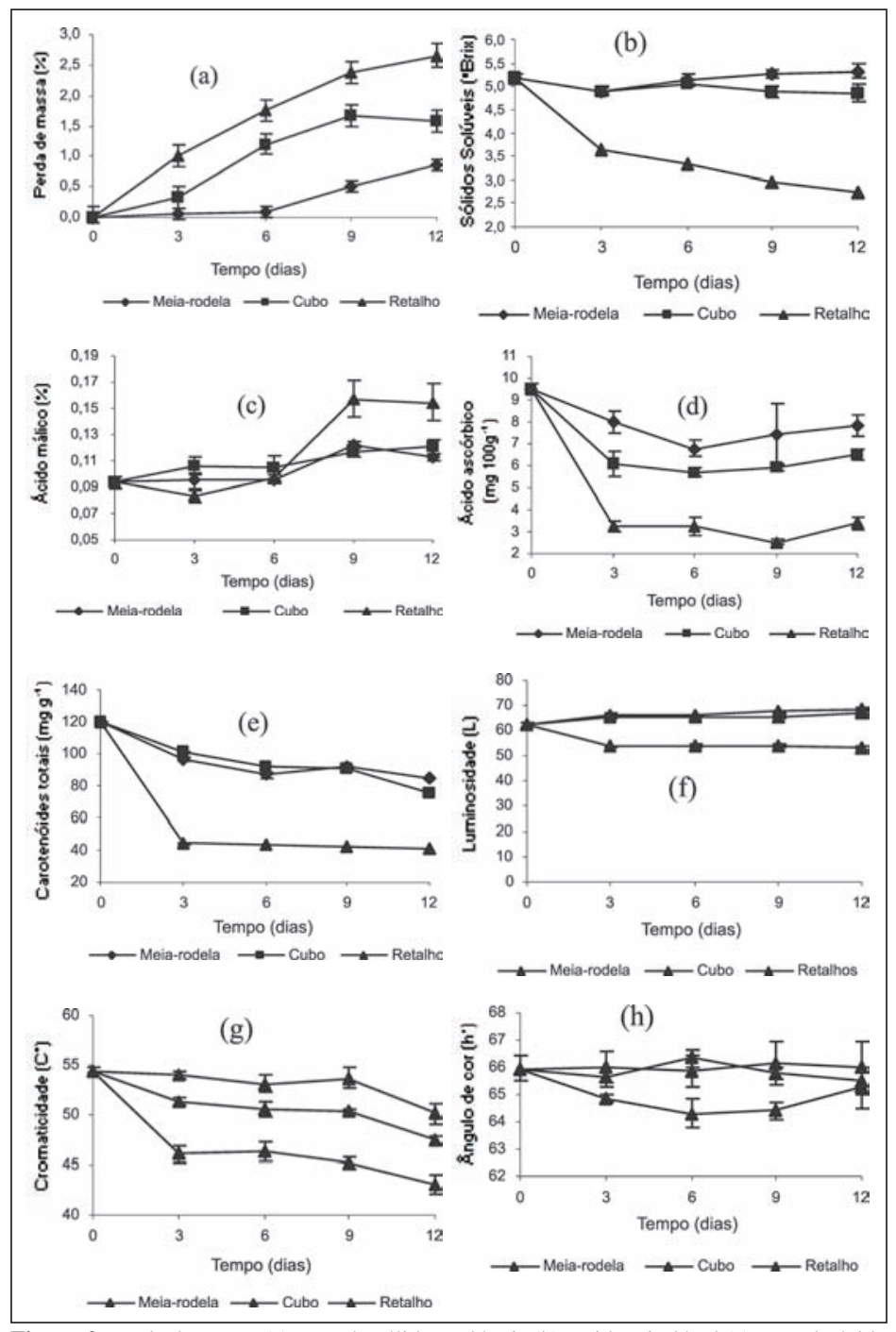

Figura 2. Perda de massa (a); teor de sólidos solúveis (b); acidez titulável (c); teor de ácido ascórbico (d); teor de carotenóides totais (e); luminosidade (f); cromaticidade (g); ângulo de cor (h); em abóboras minimamente processadas, submetidas a diferentes tipos de corte e armazenadas a $5^{\circ} \mathrm{C}^{*}$. Piracicaba, ESALQ, 2002.

*Barras verticais representam o erro padrão da média. Piracicaba, ESALQ, 2002.

te processados cortados em cubos e fatias. No corte em cubos a intensidade de cor, medida em cromaticidade $\left(\mathrm{C}^{*}\right)$, manteve-se maior ao longo de todo período de armazenamento $(53,71)$, sendo seguida pelo corte em meia-rodela e por último o corte em retalhos (Figura $2 \mathrm{~g}$ ). O corte em cubos apresentou valores de ângulo de cor $\left(\mathrm{h}^{\circ}\right)$ menores ao longo do período de armazenamento, chegando a 64,31 (Figura 2h). Os corte em meia-rodela e retalhos mantiveram praticamente os valores de ângulo de cor parecidos e constantes durante o período de armazenamento (Figura 12). Pinto (2002) também não notou mudança nos valores do ângulo de cor (hue) em melões fatiados e em cubos.

Pelo fato de não existir legislação indicando limites para contagem de bac- 
térias psicrotróficas, foram utilizados os parâmetros apresentados por Morton (2001), que permite a comercialização de vegetais congelados e similares com contagem total de bactérias aeróbicas mesófilas de até $10^{5}-10^{6} \mathrm{UFC} \mathrm{g}^{-1}$, sendo estes parâmetros os mais próximos encontrados na literatura. Até o $6^{\circ}$ dia de armazenamento os três tipos de corte apresentavam-se dentro dos limites indicados por Morton (2001). Já no último dia de análise os cortes em retalhos apresentavam-se com contagem acima do permitido $\left(2,2 \times 10^{7} \mathrm{UFC}^{-1}\right)$ sendo considerado impróprio para o consumo. No $12^{\circ}$ dia, a contagem de bactérias foi maior no corte em retalho, sendo seguido do cubo e meia-rodela, mostrando uma relação do crescimento microbiano com o tipo de corte. O corte que provocou maior injúria nos tecidos da abóbora (retalho) foi também o que apresentou maior crescimento de bactérias psicrotróficas (Tabela 1). O aumento em superfície pelo corte, dano e disponibilidade de nutrientes causados pelo processamento mínimo fornece condições que aumentam o número e os tipos de microrganismos. Além, disso, o aumento da manipulação desses produtos possibilita a contaminação por patógenos (Rosa \& Carvalho, 2000). No presente trabalho não foram detectadas presenças de coliformes (contagem total e a $45^{\circ} \mathrm{C}$ ) e Salmonella, em todos os dias de análise.

Como não existe no país uma legislação específica para os vegetais minimamente processados, os resultados foram comparados com a resolução RDC $\mathrm{n}^{\circ} 12$ da Agência Nacional de Vigilância Sanitária (ANVISA) do Ministério de Saúde, que estabelece a ausência de Salmonella (em $25 \mathrm{~g}$ de produto) e permite um máximo de $10^{2} \mathrm{NMP}$ de coliformes a $45^{\circ} \mathrm{C} \mathrm{g}^{-1}$, em hortaliças in natura. Levando em consideração esses parâmetros, os resultados estão dentro dos limites estabelecidos. Como não foram constatados coliformes e Salmonella nas amostras analisadas, infere-se que os cuidados higiênico-sanitários tomados durante o processamento mínimo foram eficientes, enquadrando o produto nos padrões microbiológicos vigentes no país.
No presente estudo, foi verificado que o tipo de corte tem influência significativa sobre a produção de etileno, aspectos qualitativos e microbiológicos das abóboras minimamente processadas. O corte que provocou maior injúria dos tecidos (retalho) mostrou taxas de produção de etileno maiores comparadas ao corte em meia-rodela, semelhante às taxas de produção de etileno dos cortes em cubos. Além disso, este corte apresentou alterações qualitativas indesejáveis, como maior perda de massa e teores de sólidos solúveis, teores menores de ácido ascórbico e de carotenóides totais. Os cortes em cubos e meia-rodela apresentaram comportamento semelhante para quase todas as variáveis analisadas.

Apesar das taxas de produção de etileno serem parecidas nos cortes em retalhos e cubos, o primeiro mostrou maiores perdas qualitativas e desenvolvimento microbiano mais acentuado, consequentemente mais rápida deterioração em relação ao último.

\section{AGRADECIMENTOS}

À Fundação de Amparo a Pesquisa do Estado de São Paulo, FAPESP, pela bolsa de mestrado concedida à primeira autora.

\section{REFERÊNCIAS}

ARRUDA MC; JACOMINO AP; KLUGE RA; AZZOLINI M. 2003. Temperatura de armazenamento e tipo de corte para melão minimamente processado. Revista Brasileira de Fruticultura 25: 74-76.

BRECHT JK. 1995. Physiology of ligthy processed fruits and vegetables. HortScience 30: 14.

CAMARGO FILHO W P; MAZZEI AR; ALVES HS. 2003. Mercado de abóboras nas cidades de São Paulo e Buenos Aires: oportunidades de expansão. Informações Econômicas 33: 6165.

CARVALHO CRL; MANTOVANI DMB; CARVALHO PRN; MORAES RM. 1990. Análises Químicas. Manual Técnico. Campinas: $121 \mathrm{p}$.

CASALI VWD; SATURNINO HM; PEDROSA JF. 1982. Botânica e origem das cucurbitáceas. Informe Agropecuário 8: 22-23.

DURIGAN JF; CASSARO KP. 2000. Hortaliças minimamente processadas. Horticultura Brasileira 18: 159-161.
FILGUEIRA FAR. 2000. Novo manual de olericultura: agrotecnologia moderna na produção e comercialização de hortaliças. Viçosa: 402p.

FINGER FL; VIEIRA G. 1997. Controle da perda pós-colheita de água em produtos minimamente processados. Viçosa: UFV. 29p.

IZUMI H; WATADA AE; KO NP; DOUGLAS W. 1996. Controlled atmosphere storage of carrots slices, sticks and shreds. Postharvest Biology and Technology 9: 165-172.

KLEIN BP; KING D; GROSSMAN S. 1985. Cooxidation reations of lipoxygenase in plant systems. Advanced Free Radical Biology and Medicine 1: 309-343.

LEE KS; KADER AA. 2000. Preharvest and postharvest factors influencing vitamin $\mathrm{C}$ content of horticultural crops. Postharvest Biology and Technology 20: 207-220.

LUENGO RFA; PARMAGNANI, RM; PARENTE MR; LIMA MFBF. 2000. Tabela de composição nutricional das hortaliças. Brasília: EMBRAPA Hortaliças. 4p.

MORETTI CL; MAROUELLI WA; SILVA WLC. 2002. Respiratory activity and browning of minimally processed sweet potatoes. Horticultura Brasileira 20: 497-500.

MORTON RD. 2001. Aerobic plate count. In: DOWNES FP; ITO K (eds). Compendium of Methods for the Microbiological Examinations of Foods. Washington: American Public Health Association. p. 63-67.

NGUYEN C; CARLIN F. 1994. The microbiology of minimally processed fresh fruits and vegetables. Critical Reviews in Food Science and Nutrition 34: 371-401.

PINTO SAA. 2002. Processamento mínimo de melão tipo Orange Fresh e de melancia 'Crimson Sweet'. Jaboticabal: UNESP. 120p (Dissertação mestrado).

PORTE A; MAIA LH. 2001. Alterações fisiológicas, bioquímicas e microbiológicas de alimentos minimamente processados. Boletim do CEPPA 19: 105-118.

RODRIGUEZ-AMAYA DB; KIMURA M. 2004. HarvestPlus handbook for carotenoid analysis. Washington DC: International Food Policy Research Institute (IFPRI). (HarvestPlus technical monography series 2).

SILVA N; JUNQUEIRA VCA; SILVEIRA NFA 2001. Manual de métodos de análises microbiológicas de alimentos. São Paulo: Varela. 317p.

ROSA OO; CARVALHO EP. 2000. Características microbiológicas de frutas e hortaliças minimamente processadas. Boletim da Sociedade Brasileira de Ciência e Tecnologia de Alimentos (SBCTA) 34: p. 84-92.

SOLIVA-FORTUNY RC; MARTIN-BELLOSO O. 2003. New advances in extending the shelflife of fresh-cut fruits: a review. Trends in Food Science \& Technology 14: 341-353.

WILEY RC. 1997. Frutas y Hortalizas Minimamente Procesadas y Refrigeradas. Zaragoza: Acribia. 362p. 